\title{
Effect of flosequinan on exercise capacity and symptoms in severe heart failure
}

\author{
J S ELBORN, C F STANFORD, D P NICHOLLS \\ From the Royal Victoria Hospital, Belfast
}

SUMMARY Twenty patients with severe chronic cardiac failure caused by ischaemic heart disease were treated with flosequinan $100 \mathrm{mg}$ daily or placebo in addition to their existing treatment with diuretics and, in some, digoxin in a randomised double blind trial. After eight weeks of treatment, flosequinan significantly improved treadmill exercise time, increased peak achieved oxygen consumption, and improved the New York Heart Association symptom grade when compared with placebo. One patient in the placebo group died and another was withdrawn because heart failure worsened. One patient in the flosequinan group was lost to follow up but there were no other withdrawals.

Flosequinan was well tolerated with few adverse effects, and it may prove to be a useful addition to diuretics and digoxin in the treatment of chronic cardiac failure.

Chronic cardiac failure is a disabling disease with a high mortality. ${ }^{1}$ Vasodilator treatment, when used in addition to diuretics, may relieve symptoms ${ }^{2}$ and help to reduce mortality. ${ }^{34}$ Flosequinan (7-fluoro-1methyl-3-methylsulphinyl-4-quinolone, Boots) is a new vasodilator that acts directly on both arterial and venous sites. ${ }^{5}$ Previous studies have indicated that it may be of value in the treatment of chronic cardiac failure. ${ }^{6-8}$

We compared the effects of flosequinan and placebo on exercise performance and symptoms in a group of patients with severe chronic cardiac failure caused by ischaemic heart disease in whom symptoms had persisted despite diuretic treatment.

\section{Patients and methods}

\section{PATIENT SELECTION}

Twenty patients with chronic cardiac failure were considered for the study. Their symptoms and treatment had been stable for at least eight weeks. All the patients had dyspnoea or fatigue on exertion (New York Heart Association grade III or IV) despite treatment with at least $80 \mathrm{mg}$ of frusemide or bumetanide $2 \mathrm{mg}$ daily, a cardiothoracic ratio on a chest radiograph of $>0.55$, and a left ventricular

Requests for reprints to Dr D P Nicholls, Royal Victoria Hospital, Grosvenor Road, Belfast BT12 6BA.

Accepted for publication 20 December 1988 ejection fraction (measured by radionuclide angiography) of $<45 \%$. Patients were excluded if exercise was limited by factors other than cardiac dyspnoea or fatigue. Other reasons for exclusion included primary valvar heart disease, hypertension, primary pulmonary disease, renal or hepatic impairment, recent myocardial infarction, or the use of cardioactive drugs other than digoxin and diuretics. All patients gave written informed consent to the study, which had been approved by the ethics committee of the Queen's University of Belfast.

\section{STUDY METHODS}

Diuretic treatment was continued unchanged throughout the trial. Seven patients receiving digoxin were also asked to continue at constant dose. During an initial single blind run-in phase on placebo that lasted at least four weeks, patients were exercised on several occasions every two weeks until their exercise duration varied by less than $10 \%$. The tests on a treadmill were symptom-limited and a modified Naughton protocol was used (table 1). Throughout each test oxygen consumption $\left(\mathrm{V}_{2}\right)$ and carbon dioxide production $\left(\mathrm{VCO}_{2}\right)$ were measured by on line expired gas analysis with a paramagnetic analyser and infrared spectrometer respectively (PK Morgan Ltd).

At entry into the study we measured the patients' resting left ventricular ejection fraction and exercise capacity (treadmill time and peak achieved $\mathrm{VO}_{2}$ ) and we assessed their symptoms by the New York Heart 
Table 1 Modified Naughton exercise protocol used to test patients with heart failure

\begin{tabular}{lll}
\hline Time $($ min) & Speed $(\mathrm{km} / \mathrm{h})$ & Incline $(\%)$ \\
\hline 4 & $1 \cdot 6$ & 0 \\
8 & $2 \cdot 4$ & 0 \\
12 & $3 \cdot 2$ & 0 \\
16 & $3 \cdot 2$ & $3 \cdot 5$ \\
20 & $3 \cdot 2$ & $7 \cdot 0$ \\
24 & $3 \cdot 2$ & $10 \cdot 5$ \\
28 & $3 \cdot 2$ & 14 \\
32 & $3 \cdot 2$ & $17 \cdot 5$ \\
\hline
\end{tabular}

Association grading. Patients answered a questionnaire on symptoms of dyspnoea and fatigue and were then randomly allocated in consecutive pairs to receive either flosequinan $100 \mathrm{mg}$ daily or a matched placebo. Exercise testing and symptom assessment were repeated after two and eight weeks of treatment, and left ventricular ejection fraction was measured at eight weeks. Blood pressure and heart rate (supine and erect), New York Heart Association symptom grade, and body weight were recorded every two weeks.

STATISTICAL ANALYSIS

Throughout the trial an independent observer constructed a sequential analysis plan by studying the patient pairs in chronological order. ${ }^{9}$ A preference was marked on the plot if at least two of the following percentage differences from baseline were seen between the two patients: exercise time $\pm 20 \%$ or more, peak $\mathrm{VO}_{2}$ achieved during exercise $\pm 20 \%$ or more, New York Heart Association symptom grade \pm one subclass. If no preference was found, no mark was made. If a patient withdrew for a treatment related reason (increasing symptoms, side effects, or death) a preference for the other treatment was noted. The plan had an overall two sided significance level $(\alpha)$ of 0.05 and a power $(1-\beta)$ of 0.95 , when it was assumed that the ratio of preferences between the treatments was 0.95:0.05.

On completion of the study we analysed exercise time, peak achieved $\dot{\mathrm{V}}_{2}$, left ventricular ejection fraction, and New York Heart Association grade in a fixed sample size design, using Wilcoxon's signed rank test for comparisons within groups and the Mann-Whitney test for comparisons between groups ( $p<0.05$ was regarded as significant). In each case, changes from baseline during treatment were compared between the groups rather than the absolute values, and all available data were used at each time point. Blood pressure, heart rate, and body weight were compared by analysis of covariance with repeated measures.

\section{Results}

The trial was stopped when seven preferences in $\overrightarrow{\vec{F}}$ favour of the active drug had been noted. The upper boundary on the sequential analysis plan had been $\frac{5}{5}$ reached after six patient pairs had completed week $8 \frac{\mathrm{O}}{\mathrm{c}}$. (p < 0.05) (fig 1), but the final pair were allowed to $\frac{\sigma}{\sigma}$ complete the trial. To reach this point, ten patient $\propto$ pairs had been entered. In three pairs, no preference could be determined; in no pair was placebo $\overrightarrow{0}$ preferred. In one pair (no 1) the patient on placebo developed an inflammatory arthritis and withdrew $\bar{\sigma}^{-}$ from the trial. This did not count as a preference for active drug. In another pair (no 5) the patient on placebo died after an episode of ventricular tachy- $-\frac{9}{-}$ cardia, but the patient on active drug was lost to ${ }_{\omega}^{+}$ follow up, so no preference could be determined. In the third pair (no 8) the differences between the twoo patients were not great enough (exercise time $+8 \%$ 工 and peak achieved $\dot{\mathrm{VO}}_{2}-1 \%$ in favour of active $\triangle$ treatment, New York Heart Association grade을. improved on active treatment but deteriorated on $\vec{\oplus}$ placebo treatment). In addition, one patient ono placebo (no 2) withdrew because of deterioration of ${ }^{\circ}$

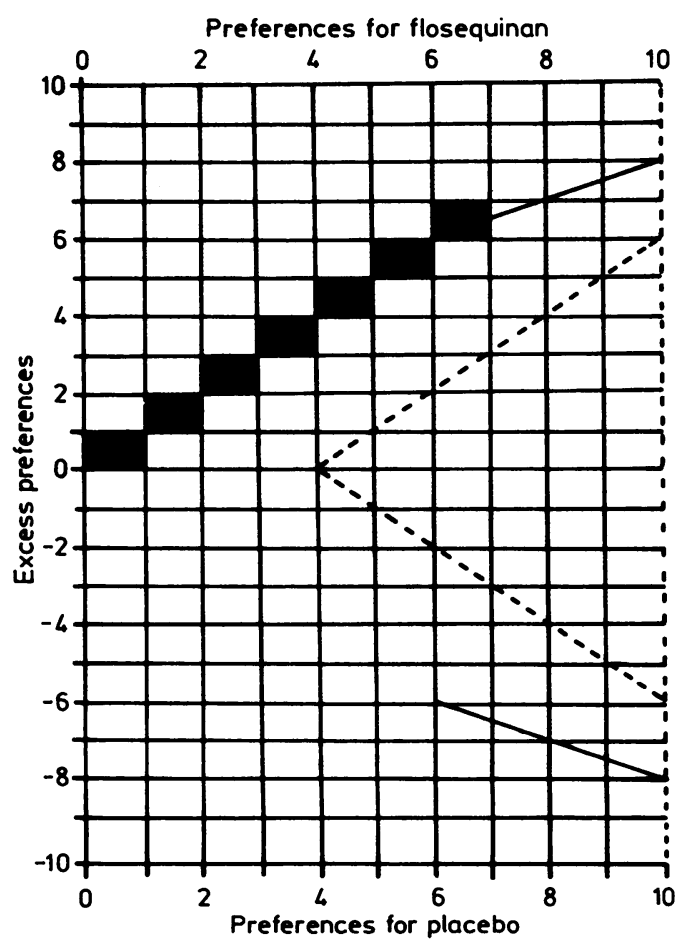

Fig 1 Sequential analysis plan for active treatment (flosequinan) against placebo. Significance level 5\%. Power $95 \%$ to predict a proportion of preferences of 0.95:0.05. 
Table 2 Details of patient pairs on entry (week 0) into the study

\begin{tabular}{|c|c|c|c|c|c|c|c|c|}
\hline \multicolumn{2}{|c|}{ Pair no } & \multirow{2}{*}{$\begin{array}{l}\text { Age }(y r) \\
38\end{array}$} & \multirow{2}{*}{$\begin{array}{l}\begin{array}{l}\text { Duration of } \\
\text { disease }(y r)\end{array} \\
1.5\end{array}$} & \multirow{2}{*}{$\begin{array}{l}\begin{array}{l}\text { NYHA } \\
\text { grade }\end{array} \\
\text { IIIb }\end{array}$} & \multirow{2}{*}{$\begin{array}{l}\begin{array}{l}\text { LVEF } \\
(\%)\end{array} \\
18\end{array}$} & $\begin{array}{l}\text { Diuretic/digoxin } \\
\text { dose (daily) }\end{array}$ & \multicolumn{2}{|c|}{$\begin{array}{l}\text { Other treatment } \\
\text { (daily) }\end{array}$} \\
\hline 1 & $\mathbf{F}$ & & & & & Fr $120 \mathrm{mg}$ & & \\
\hline & $\mathbf{P}$ & 63 & 4 & IV & 20 & $\begin{array}{lc}\text { Fr } & 80 \mathrm{mg} \\
\mathrm{D} & 125 \mu \mathrm{g} \\
\mathrm{A} & 10 \mathrm{mg}\end{array}$ & $\begin{array}{l}\text { A1 } \\
\text { M }\end{array}$ & $\begin{array}{r}100 \mathrm{mg} \\
1500 \mathrm{mg}\end{array}$ \\
\hline \multirow[t]{2}{*}{2} & $\mathbf{F}$ & 69 & 3 & IIIb & 24 & $\begin{array}{lr}\text { B } & 3 \mathrm{mg} \\
\text { A } & 15 \mathrm{mg}\end{array}$ & W & $3 \mathrm{mg}$ \\
\hline & $\mathbf{P}$ & 62 & 3 & IIIb & 30 & $\begin{array}{lr}\text { Fr } & 120 \mathrm{mg} \\
\text { A } & 15 \mathrm{mg}\end{array}$ & & \\
\hline \multirow[t]{2}{*}{3} & $\mathbf{F}$ & 59 & 4 & IIIa & 27 & $\begin{array}{ll}\text { Fr } & 80 \mathrm{mg} \\
\text { A } & 10 \mathrm{mg}\end{array}$ & $\begin{array}{l}\mathbf{W} \\
\mathbf{P}\end{array}$ & $\begin{array}{r}5 \mathrm{mg} \\
75 \mathrm{mg}\end{array}$ \\
\hline & $\mathbf{P}$ & 68 & 2 & IIIa & 27 & $\begin{array}{ll}\text { Fr } & 80 \mathrm{mg} \\
\text { A } & 10 \mathrm{mg}\end{array}$ & & \\
\hline \multirow[t]{2}{*}{4} & $\mathbf{F}$ & 51 & 2 & IIIa & 18 & $\begin{array}{lr}\mathrm{Fr} & 80 \mathrm{mg} \\
\mathrm{A} & 10 \mathrm{mg} \\
\mathrm{D} & 250 \mu \mathrm{g}\end{array}$ & $\begin{array}{l}\text { W } \\
\text { Am }\end{array}$ & $\begin{array}{r}9 \mathrm{mg} \\
200 \mathrm{mg}\end{array}$ \\
\hline & $\mathbf{P}$ & 56 & 3 & IIIb & 18 & $\begin{array}{lr}\mathrm{Fr} & 80 \mathrm{mg} \\
\mathrm{A} & 10 \mathrm{mg} \\
\mathrm{D} & 125 \mu \mathrm{g}\end{array}$ & $\mathbf{W}$ & $5 \mathrm{mg}$ \\
\hline \multirow[t]{2}{*}{5} & $\mathbf{F}$ & 52 & 4 & IIIb & 42 & $\begin{array}{ll}\text { Fr } & 80 \mathrm{mg} \\
\text { A } & 10 \mathrm{mg}\end{array}$ & & \\
\hline & $\mathbf{P}$ & 71 & 7 & IIIb & 37 & $\begin{array}{ll}\mathrm{Fr} & 80 \mathrm{mg} \\
\mathrm{A} & 10 \mathrm{mg}\end{array}$ & & \\
\hline \multirow[t]{2}{*}{6} & $\mathbf{F}$ & 69 & 4 & IV & 18 & $\begin{array}{ll}\text { Fr } & 80 \mathrm{mg} \\
\text { A } & 10 \mathrm{mg}\end{array}$ & & \\
\hline & $\mathbf{P}$ & 66 & 0.5 & IIIb & 24 & $\begin{array}{lr}\text { Fr } & 80 \mathrm{mg} \\
\text { A } & 10 \mathrm{mg} \\
\text { D } & 125 \mu \mathrm{g}\end{array}$ & & \\
\hline \multirow[t]{2}{*}{7} & $\mathbf{F}$ & 66 & 4 & IIIb & 33 & $\begin{array}{lr}\text { Fr } & 120 \mathrm{mg} \\
\text { A } & 15 \mathrm{mg} \\
\text { D } & 125 \mu \mathrm{g}\end{array}$ & W & $3 \mathrm{mg}$ \\
\hline & $\mathbf{P}$ & 58 & 3 & IIIb & 31 & $\begin{array}{lr}\text { Fr } & 120 \mathrm{mg} \\
\mathrm{A} & 15 \mathrm{mg}\end{array}$ & & \\
\hline \multirow[t]{2}{*}{8} & $\mathbf{F}$ & 59 & 4 & IIIb & 23 & $\begin{array}{ll}\text { Fr } & 80 \mathrm{mg} \\
\text { A } & 10 \mathrm{mg}\end{array}$ & C & $800 \mathrm{mg}$ \\
\hline & $\mathbf{P}$ & 63 & 1.5 & IIIb & 30 & $\begin{array}{ll}\mathrm{Fr} & 80 \mathrm{mg} \\
\mathrm{A} & 10 \mathrm{mg}\end{array}$ & & \\
\hline \multirow[t]{2}{*}{9} & $\mathbf{F}$ & 66 & 4 & IIIb & 25 & $\begin{array}{lr}\text { Fr } & 80 \mathrm{mg} \\
\text { A } & 10 \mathrm{mg} \\
\text { D } & 125 \mu \mathrm{g}\end{array}$ & & \\
\hline & $\mathbf{P}$ & 72 & 4 & IIIa & 23 & $\begin{array}{ll}\mathrm{Fr} & 80 \mathrm{mg} \\
\mathrm{A} & 10 \mathrm{mg}\end{array}$ & & \\
\hline \multirow[t]{2}{*}{10} & $\mathbf{F}$ & 66 & 1 & IIIb & 36 & $\begin{array}{ll}\mathrm{Fr} & 80 \mathrm{mg} \\
\mathrm{A} & 10 \mathrm{mg}\end{array}$ & & \\
\hline & $\mathbf{P}$ & 62 & 2 & IIIa & 21 & $\begin{array}{ll}\mathrm{Fr} & 80 \mathrm{mg} \\
\mathrm{A} & 10 \mathrm{mg}\end{array}$ & & \\
\hline \multirow{2}{*}{\multicolumn{2}{|c|}{ Mean $(S D) F$}} & $59(10)$ & $3 \cdot 1(1 \cdot 2)$ & IIIb† & $27(8)$ & $\begin{array}{ll}\mathrm{Fr}^{\star} & 92(19) \mathrm{mg} \\
\mathrm{A} & 12(4) \mathrm{mg}\end{array}$ & & \\
\hline & & $64(5)$ & $3.0(1 \cdot 7)$ & IIIb† & $26(6)$ & $\begin{array}{l}\mathrm{Fr}^{\star} 92(19) \mathrm{mg} \\
\mathrm{A} \quad 11(2) \mathrm{mg}\end{array}$ & & \\
\hline
\end{tabular}

*Assuming $1 \mathrm{mg}$ bumetanide $\bumpeq \mathbf{4 0} \mathrm{mg}$ frusemide.

+Median.

F, flosequinan; P, placebo; Fr, frusemide; B, bumetanide; A, amiloride; D, digoxin; Al, allopurinol; M, metformin; P, prothiaden; Am, amiodarone; C, cimetidine; $W$, warfarin; LVEF, left ventricular ejection fraction.

his symptoms; this was counted as a preference for active drug.

All the patients studied were men (table 2) and had electrocardiographic evidence of previous myocardial infarction. Two patients in each group had a previous history of hypertension. Table 3 shows the absolute values for exercise time, peak achieved $\mathrm{Vo}_{2}$, left ventricular ejection fraction, and New York Heart Association symptom grade. Baseline exercise time and peak achieved $\mathrm{Vo}_{2}$ were greater in the group on active treatment than in the placebo group but these differences were not significant. There were no significant improvements in either exercise time or peak achieved $\mathrm{VO}_{2}$ during placebo treatment, but significant increases were seen after two weeks of treatment with flosequinan, which continued to eight weeks (table 3). Mean exercise time improved over baseline by 230 seconds ( $95 \%$ confidence interval 88.4 to 538.2 s) at week 2 and by 243 (83.2 to 404.6$)$ seconds at week 8 , compared with changes on placebo of $-71(-144.3$ to $2 \cdot 3)$ seconds and $-84(-197 \cdot 5$ to $28 \cdot 7$ ) seconds respectively. Peak achieved $\mathrm{Vo}_{2}$ on flosequinan was $2.5(0.9$ to 4.1$) \mathrm{ml} / \mathrm{min} / \mathrm{kg}$ higher than baseline at week 2 and $2.4(0.8$ to 4.0$) \mathrm{ml} / \mathrm{min} / \mathrm{kg}$ 
Table 3 Response to flosequinan and placebo (mean (95\% confidence interval))

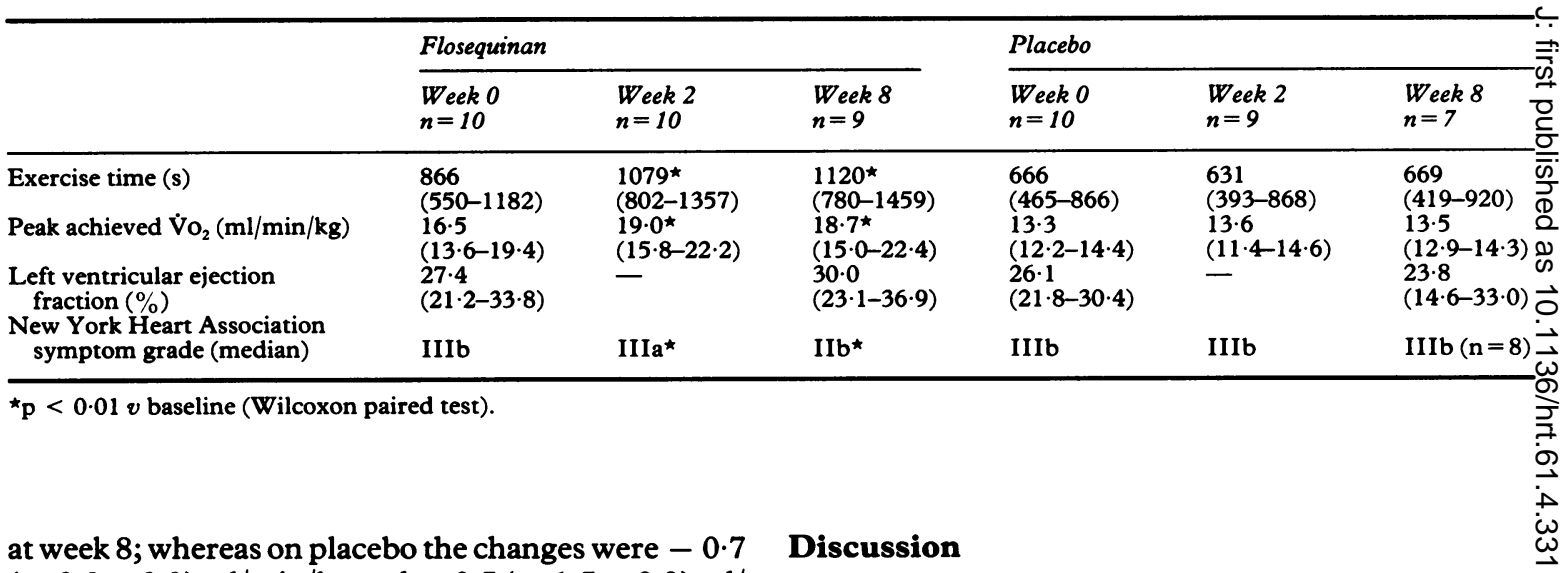

$(-2.3$ to 0.9$) \mathrm{ml} / \mathrm{min} / \mathrm{kg}$ and $-0.5(-1.5$ to 0.9$) \mathrm{ml} /$ $\mathrm{min} / \mathrm{kg}$ respectively. There was a small increase in left ventricular ejection fraction during treatment with flosequinan $(4.1(-0.1$ to 8.3$) \%$ at week 8$)$, while the change on placebo was $-0.5(-9.2$ to $8 \cdot 2) \%$. Figure 2 shows the significance values for these changes. There was no change in New York Heart Association symptom grade after placebo, whereas symptoms progressively improved from a median value of IIIb to IIIa at two weeks $(p<0.01)$ and to IIb at eight weeks ( $p<0.001)$ during treatment with flosequinan.

There were small reductions in body weight after both treatments; neither was significant. Blood pressure at rest, standing, and at maximum exercise was unchanged by both treatments. There were significant changes in resting and standing heart rate. During placebo treatment, supine heart rate fell from a mean value of 80.9 to 72.6 beats $/ \mathrm{min}$ at week 8 , whereas during treatment with flosequinan heart rate increased from 80.1 to 90.7 beats $/ \mathrm{min}$. The difference between the treatments was significant ( $p$ $=0.001$ ). Standing heart rate fell from 88.3 to 79.0 beats/min on placebo, and increased from 91.4 to 102.0 beats $/ \mathrm{min}$ on flosequinan (difference $p$ $=0.004)$. A small increase in peak exercise heart rate was also seen after flosequinan, but this was not significant. Symptoms of breathlessness, reported on a patient questionnaire, were improved after flosequinan ( $p=0.002 v$ placebo), as were those of fatigue ( $p=0.02 v$ placebo)

There were no serious adverse effects on placebo (other than those noted above) that necessitated withdrawal from the trial. While on flosequinan, one patient had an episode of wheezing which promptly responded to inhaled $\beta_{2}$ agonists; he had suffered intermittent wheezing for many years. Another had effort syncope, but this was found to be caused by hypoglycaemia.
Peripheral vasoconstriction is a prominent feature of ${ }_{-}^{\circ}$ the vascular response to chronic cardiac failure. ${ }^{10} \frac{D}{D}$ Vasodilator drugs reduce cardiac afterload, preload, 을. or both. Flosequinan is active at both arterial and $\vec{\oplus}$ venous sites, ${ }^{5}$ but its precise mechanism of action is ${ }_{0}^{\circ}$ unknown. The action does not involve adrenoceptors. ${ }^{\circ}$ or calcium channels, but may result from an increase in the level of membrane bound cyclic guanosine monophosphate. ${ }^{11}$ Although vasodilatation is a⿳亠丷厂 logical treatment for chronic cardiac failure, the useo of many such drugs has been limited by the develop- $\propto$ ment of tolerance. ${ }^{12}$ Experience with prazosin $\overrightarrow{0}$ indicates that attenuation of effect is seen after four to 3 eight weeks of treatment. ${ }^{13-15}$ The present study? suggests that tolerance does not occur within eight? weeks of treatment with flosequinan, because the
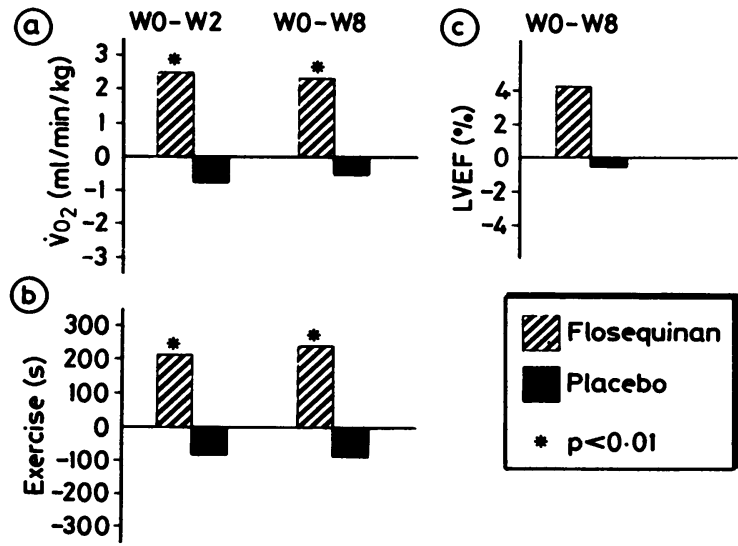

Fig 2 Changes in mean (a) peak $\dot{V}_{2}(\mathrm{ml} / \mathrm{min} / \mathrm{kg}$ ), (b) exercise time, and (c) left ventricular ejection fraction $(\%)$ in the flosequinan group compared with placebo at week 0 to week 2 and week 0 to week 8. ${ }^{\star} p<0.01$ (MannWhitney $U$ test). 
weeks of treatment with flosequinan, because the beneficial effects recorded at two weeks were still seen after eight weeks of drug administration. However, longer term studies will be required to exclude the eventual development of tolerance.

Although many studies have shown favourable acute haemodynamic responses to vasodilator drugs, there are few longer term randomised controlled trials. ${ }^{16}$ One limitation is the high mortality of the condition, which makes lengthy trials difficult to conduct. There also may be reluctance to include a placebo treated group in trials on patients with severe chronic cardiac failure, but we consider that a limited number of such trials should be conducted. In order not to prolong the trial beyond what is necessary to prove a difference, we used the sequential analysis technique to allow a continuous overview of trial progress.

Haemodynamic measurements and other standard indices of left ventricular performance (such as ejection fraction) correlate poorly with symptoms and exercise capacity in patients with chronic cardiac failure. ${ }^{17} 18$ In contrast, exercise testing with measurement of respiratory gas exchange closely reflects symptoms ${ }^{1920}$ and is a reliable objective method of assessment of disease progress. ${ }^{21}$ In the present study there was a significant increase in peak achieved $\mathrm{VO}_{2}$ during exercise after two weeks of active treatment, and this was sustained to eight weeks. No such improvement was seen after placebo, which would exclude a training effect associated with repeated exercise testing, even though the tests were infrequent. We also saw a significant improvement in symptom grade after active treatment.

There were few adverse effects, and the single death during the trial (on placebo) is not unexpected in a group of patients with severe chronic cardiac failure. We conclude that flosequinan may prove to be of value in the treatment of patients with diuretic resistant heart failure.

We thank Dr R Bratty, Dr R Wynne, and Mr D J McEntegart of the Statistical Department of the Boots Company for their advice and support. JSE was in receipt of a Royal Victoria Hospital research fellowship.

\section{References}

1 Wilson JR, Schwartz JS, Sutton M St J, et al. Prognosis in severe heart failure: relation to hemodynamic measurements and ventricular ectopic activity. $\mathrm{J} \mathrm{Am}$ Coll Cardiol 1983;2:403-10.

2 Packer $M$. Vasodilator and inotropic therapy for severe chronic heart failure: passion and skepticism. $\mathrm{J} \mathrm{Am}$ Coll Cardiol 1983;2:841-52.

3 CONSENSUS Trial Study Group. Effects of enalapril on mortality in severe congestive heart failure. $N E n g l$ J Med 1987;316:1429-35.

4 Cohn JN, Archibald DG, Ziesche S, et al. Effect of vasodilator therapy on mortality in chronic congestive heart failure. Results of a Veterans Administration Cooperative Study. N Engl J Med 1986;314:1547-52.

5 Cowley AJ, Wynne R, Hampton JR. The effects of BTS 49465 on blood pressure and peripheral arteriolar and venous tone in normal volunteers. $J$ Hypertens 1984;2(suppl 3):547-9.

6 Kessler PD, Packer M. Hemodynamic effects of BTS 49465, a new long-acting systemic vasodilator drug, in patients with severe congestive heart failure. $\mathrm{Am}$ Heart $J$ 1987;113:137-43.

7 Silke B, Verma SP, Taylor SH. A haemodynamic and treadmill exercise study with flosequinan in mild chronic heart failure [Abstract]. Br J Clin Pharmacol 1987;24:250P-1P.

8 Cowley AJ, Wynne RD, Stainer K, Fullwood L, Rowley JM, Hampton JR. Flosequinan in heart failure: acute haemodynamic and longer term symptomatic effects. Br Med J 1988;297:169-73.

9 Armitage P. Sequential medical trials. Oxford: Blackwell, 1975.

10 Zelis R, Flaim SF. Alterations in vasomotor tone in congestive heart failure. Prog Cardiovasc Dis 1982; 24:437-59.

11 Allcock AA, Frodsham G, Sim MF. Effects of flosequinan, a novel arteriovenous dilating agent, on cGMP levels in rat isolated aortic strips [Abstract]. $\mathrm{Br}$ $J$ Pharmacol 1988;94:430P.

12 Colucci WS, Williams GH, Alexander RW, Braunwald E. Mechanisms and implications of vasodilator tolerance in the treatment of congestive heart failure. Am J Med 1981;71:89-99.

13 Colucci WS, Wynne J, Holman BL, Braunwald E. Long-term therapy of heart failure with prazosin: a randomized double blind trial. Am J Cardiol 1980; 45:337-44.

14 Harper RW, Claxton H, Middlebrook K, Anderson S, Pitt $\mathbf{A}$. The acute and chronic haemodynamic effects of prazosin in severe congestive cardiac failure. Med $J$ Aust 1980;ii:(suppl):36-8.

15 Bayliss J, Norell MS, Canepa-Anson R, Reid C, PooleWilson P, Sutton G. Clinical importance of the reninangiotensin system in chronic heart failure: double blind comparison of captopril and prazosin. $\mathrm{Br} M e d J$ 1985;290:1861-5.

16 Lipkin DP, Poole-Wilson PA. Treatment of chronic heart failure: a review of recent drug trials. $\mathrm{Br} \mathrm{Med} \mathrm{J}$ 1985;291:993-6.

17 Franciosa JA, Park M, Levine B. Lack of correlation between exercise capacity and indexes of resting left ventricular performance in heart failure. $\mathrm{Am} \mathrm{J} \mathrm{Car-}$ diol 1981;47:33-9.

18 Elborn JS, Stanford CF, McNair W, Nicholls DP. Relationship of left and right ventricular ejection fraction to exercise capacity and symptom status in patients with chronic cardiac failure [Abstract]. Clin Sci 1987;73(suppl 17):23P.

19 Patterson JA, Naughton J, Pietras RJ, Gunnar RM. Treadmill exercise in assessment of the functional capacity of patients with cardiac disease. Am J Cardiol 1972;30:757-62.

20 Lipkin DP, Perrins J, Poole-Wilson PA. Respiratory gas exchange in the assessment of patients with impaired ventricular function. Br Heart $J$ 1985; 54:321-8.

21 Lipkin DP. The role of exercise testing in chronic heart failure. Br Heart J 1987;58:559-66. 